\section{Ironing out greenhouse effects}

Robin S. Keir

IT has been proposed that $\mathrm{CO}_{2}$ could be removed from the atmosphere and thereby its greenhouse effect reduced by using the so-called 'iron hypothesis' of Martin'. According to this idea, iron is the limiting nutrient for biological growth in Antarctic surface waters, which have abundant phosphate, nitrate and silicate. By fertilizing this area with iron, phytoplankton growth would be greatly stimulated, and the surface-water's partial pressure of $\mathrm{CO}_{2}$ would be greatly reduced - by more than 150 parts per million (p.p.m.). But even if the fertilization were completely successful, the effect on atmospheric $\mathrm{CO}_{2}$ would be much smaller according to Peng and Broecker on page 227 of this issue ${ }^{2}$. Their model calculations show that after 100 years of successful fertilization, the atmospheric $\mathrm{CO}$, content would be reduced oniy by about 30 p.p.m., an amount which is also small in comparison to the hundreds of parts per million the concentration is projected to rise during this time owing to fossil-fuel burning.

The authors point out that the problem is that the capacity of the Antarctic surface water by itself to take up atmospheric $\mathrm{CO}$, is very small. Therefore this region acts only as an interface through which additional $\mathrm{CO}_{2}$ could be sequestered from the atmosphere and transferred into the large volume of intermediate and deep waters. The rate of this transfer depends upon the nature of the circulation: the speed with which the upper waters are replaced and the extent to which they remain in contact with the atmosphere afterwards.

The model simulations on page 228 (their Fig. 3) illustrate this aspect quite clearly. Initially there is a transitory period of a few years during which the $\mathrm{CO}_{2}$ partial pressure $\left(p_{\mathrm{CO}}\right)$ in the surface water decreases rapidly and subsequently recovers to within 30 p.p.m. or so of the atmospheric value. The latter evidently occurs because of rapid exchange of $\mathrm{CO}_{2}$ across the sea surface. After this transient, the surface $p_{\mathrm{CO}}$ maintains a nearly constant disequilibrium with the atmosphere. The resulting decrease in atmospheric $\mathrm{CO}_{2}$ is quite slow; the time constant is probably of the order of a few hundred years ${ }^{3}$. The Antarctic surface water is flushed every few years by the circulation, but for every turnover, the water takes up only a small part of the atmospheric $\mathrm{CO}_{2}$ so that the time constant for $\mathrm{CO}$, removal is about 100 times the water residence time.

The result found by Peng and Broecker is bound to be somewhat model dependent. Indeed, Joos et al. ${ }^{4}$, using a different circulation pattern through the Antarctic surface region and larger surface area, find that the disequilibrium between the atmospheric and Antarctic surface water $p_{\mathrm{CO}}$ is maintained at a larger value. The consequent reduction in the rate of increase of atmospheric $\mathrm{CO}_{2}$ is also some-

Surely in looking at how to tackle the threat of greenhouse warming, we should not focus on which model of iron fertilization gives the best result (the possibility of undesirable ecological effects put to one side for the moment), but rather we should worry about the increasing rates of fossil-fuel consumption. The total scale of fossil-fuel reserves is not known with any certainty, but most estimates are between 6 and 12 times the present amount of carbon in the atmosphere as $\mathrm{CO}$, mostly as coal ${ }^{5}$. Barring increased uptake by the terrestrial biosphere, which seems unlikely because of deforestation, 70-80 per cent of this carbon will accumulate in the atmosphere if it is burned over a period of a few hundred years, regardless of the actual history of the $\mathrm{CO}_{2}$ generation over this period". When we have consumed most of the fossil fuel, the atmosphere will have reached a level of at least 1,500 p.p.m. from its present level of around 345 p.p.m.: at this point it may mot matter whether a sequestering effort reduced the atmospheric $\mathrm{CO}_{2}$ by 30 p.p.m. or 300 p.p.m.

However, exactly when the maximum $\mathrm{CO}_{2}$ level will be reached can vary greatly. For example, a slowly growing production of $\mathrm{CO}_{2}$ may result in only a doubling of the atmospheric content by the year 2100 , but expansion of $\mathrm{CO}_{2}$ production at the pre1973 rate of 4.5 per cent a year could lead to levels over 1,200 p.p.m. by then". Because fossil fuel is a finite resource, we will need to find an alternative within the next two or three centuries (sooner if substantial consumption of coal is to be avoided). The slower that fossil fuel is burned in the meantime, the better. Neither iron fertilization nor any other method of $\mathrm{CO}_{2}$ sequestration can be considered a serious alternative.

Robin S. Keir is at GEOMAR, Forschungszentrum für Marine Geowissenschaften an der Christian-Albrechts-Universität zu Kiel, Wischhofstrasse 1-3, $2300 \mathrm{Kiel} 14$, Germany.

1. Martin, J. H. Paleoceanography 5, 1-13 (1990).

2. Peng, T.-H. \& Broecker, W. S. Nature 349, 227-229 (1991)

3. Wenk, T. \& Siengenthaler, U. in The Carbon Cycle and Atmospheric $\mathrm{CO}_{2}$ : Natural Variations Archean to Present (eds Sundquist, E. T. \& Broecker, W. S.) 185-194 (American Geophysical Union, Washington DC, 1985)

. Joos, F., Sarmiento, J. L. \& Siegenthaler, U. Nature (in the press).

5ress). Rotty, R. M. \& Marland, G., in Interactions of Energy and Climate (eds Bach, W., Pankrath, J. \& Williams, J.)

6. Keeling, C. D. \& Bascastow, R. B in Energy and Climate 72-95 (National Academy of Sciences, Washington DC, 1977) what greater. 191-212 (Reidel, Dordrecht, 1988)

\section{In two minds}

$\mathrm{E}_{\mathrm{ACH}}$ hemisphere of the human brain has its own specialism. The left hemisphere (which dominates the right side of the body) is good at language and logic; the right hemisphere (dominating the left side) has better spatial awareness and emotional intuition. Daedalus points out how our view of a knotty problem tends to shift cyclically back and forth every few hours or so. This, he says, is our two hemispheres looking at the matter in turn.

He relates this alternation of mood to our nostrils, which have to warm and humidify the air before it reaches our lungs. It's a hard job. It can drain 5-15 watts of heat continuously from the warming and wetting surfaces, and the nostrils tend to open alternately, a few hours at a time. (You notice this when you have a cold.) Each hemisphere of the brain puts out only about 10 watts of heat. The active nostril, draining heat copiously from the hemisphere close above it, must cool it strongly. The brain is very sensitive to temperature, growing feverish in the warm and sleepy in the cold. So as each nostril opens up in turn, the hemisphere on that side grows sleepy, and our mood swings accordingly.

In this connection, Daedalus recalls the traditional yoga exercise of breathing in through one nostril and out the other. The nostril of inflow gets no relief from warm exhaled breath, and must cool its hemisphere very strongly - a subtle yogic way of opening the mind to new perceptions. Daedalus's 'psychonasal air-conditioner' provides each nostril with its own air, of defined temperature and humidity. It can fire up or chill out either hemisphere at will. Plumbed into the prototype, DREADCO volunteers are tackling the usual psychiatrists' battery of insulting questions and emotional ordeals. With its aid, the sternest logicians are enjoying flights of fancy, while poets buckle down to mathematical proofs.

The final 'Psyconditioner' will be a special hat with concealed plumbing and heat-pump, and integral nose-piece. By controlling the wearer's nostril-air, it will expand his consciousness under full control. Modern, highly verbal society tends to put the right hemisphere at a disadvantage; but the Psyconditioner will allow anyone to get in touch with his intuitive nature. Its wearer will be able to look at a problem first logically, then intuitively - then (with the aid of a special superheater) with fevered imagination, and even with fevered logic. At a picture-gallery or social function he will engage his right hemisphere, while the small print of an insurance-contract will engross his left one. The most inhibited or undisciplined wearer will be able to experience previously suppressed aspects of his personality - and suppress them again as necessary.

David Jones 